\title{
FACTORES DE ACCESO Y PERMANENCIA DE LA ÉLITE Política Gubernamental en Chile (1990-2010)
}

Bastián González Bustamante (bastiangb@ug.uchile.cl)

CISPO, Universidad de Los Lagos

Este artículo analiza los factores de acceso y permanencia de la élite política gubernamental en Chile para el período 1990-2010. Se trabaja con datos de una encuesta de 386 miembros de la élite quienes fueron parte del campo político. Sólo 199 casos de la encuesta califican como parte de la élite gubernamental. Se presenta una descripción del grupo, un índice de permanencia destacada y un modelo de regresión logística binaria acompañado de un Análisis Comparado Cualitativo (QCA). Se evidencia un grupo homogéneo y que los factores que determinan el acceso no son los mismos que determinan la permanencia. En consecuencia, si bien el perfil técnico favorece el acceso, el capital político y la participación previa en think tanks resultan relevantes para la permanencia en las posiciones políticas más altas.

Palabras clave: Élite politica, capital político, think tanks, QCA, Chile.

\section{FACTORS AFFECTING ACCESS AND PERMANENCE OF THE Governmental Political elite in Chile (1990-2010)}

This article analyzes the factors affecting access and permanence of the governmental political elite in Chile from 1990 to 2010, utilizing data from a survey of 386 members of the elite who entered the political field. Only 199 cases from the survey qualify as part from the governmental elite. It presents a description of the group, a relevant permanence index, and a logistic binary regression model together with a Qualitative Comparative Analysis (QCA). The results find a homogeneous group, and that the factors affecting access are not the same as those for permanence. It concludes that, although a technical profiles facilitates access, political capital and previous participation in think tanks are more relevant for permanence in the highest political positions.

Keywords: Political elite, political capital, think tanks, QCA, Chile. 


\section{Introducción $^{1}$}

El estudio de las élites ha sido un tema recurrente en las ciencias sociales desde comienzos del siglo pasado, especialmente en lo que respecta a las élites políticas y económicas. Con respecto al estudio de las élites políticas cabe señalar que existe un interés persistente por saber quiénes son y qué características poseen las personas que ejercen el gobierno y se desempeñan en el campo político.

Entender la sociología y funcionamiento de la élite política, a través de una caracterización de su composición y de sus procesos de reclutamiento y circulación, es un tipo de estudio recurrente e importante que permite entender la relación entre los partidos políticos y los procesos de decisión política más allá de lo meramente institucional. En este sentido, el acceso al poder político tiene una fuerte relación con los procesos de reclutamiento y con la profesionalización de la actividad política en un sentido weberiano. Comprender la formación de elencos elitarios permite comprender cómo grupos de personas acceden a posiciones institucionales - algunas más relevantes que otras- y se transforman (o no) progresivamente en políticos profesionales.

El acceso a posiciones relevantes en la élite política es un punto importante en la trayectoria individual de un actor, esto en el contexto de una red social donde tal actor acumula distintos tipos de recursos y capitales. En esta línea, los partidos políticos juegan un rol importante, pues permiten que un actor acceda a posiciones relevantes gracias a su trayectoria política, profesional, o social. La trayectoria particular de un actor genera un interés del mundo político, lo que le permite acceder, luego de ser reclutado, a diversas posiciones de privilegio en el campo político. Todo lo anterior gracias al apoyo partidario. Esto no significa que actores sin militancia política no puedan reconvertir sus capitales y pasar del campo social (u otro) al campo político, sólo significa que les suele resultar mucho más dificil si no lo hacen al alero de un partido político.

El estudio de los partidos políticos y la institucionalidad permiten dar cuenta del rol que tienen estas organizaciones en materia de representación e intermediación entre la sociedad civil y otros actores del sistema político. Lo anterior se da particularmente en lo que respecta a agregación de intereses, preferencias, y canalización de

\footnotetext{
Esta investigación fue soportada por el proyecto 1100877 del Fondo Nacional de Desarrollo Científico y Tecnológico (Alfredo Joignant, Investigador Principal). Agradezco especialmente a Gonzalo Delamaza, Jaime Baeza y Mireya Dávila por sus excelentes comentarios y recomendaciones. También agradezco los comentarios de revisores anónimos, los cuales me permitieron mejorar este trabajo.
} 
demandas. En contrapartida a este tipo de estudios de carácter más institucional se encuentran los estudios sobre combinaciones de recursos y capitales de los actores, junto con el estudio de sus trayectorias. Este tipo de investigaciones permiten entender qué factores son determinantes para el acceso a posiciones relevantes en la élite y la permanencia prolongada en dichas posiciones. Lo anterior no solo implica vislumbrar estructuras de capital, concepto ligado a la teoría de campos, habitus y capitales (ver Bourdieu, 1984, 1986, 1996, 1999), sino también ofrece un panorama sobre los códigos "no escritos" que imperan en el campo político, los cuales influyen en los procesos de reclutamiento, en las trayectorias de los distintos agentes, e incluso en los procesos de toma de decisiones.

Cabe entonces preguntarse, ¿qué factores determinan que ciertos actores accedan a las posiciones más relevantes en la élite política? ¿Por qué ciertos casos verifican mayor permanencia que otros? ¿Qué factores condicionan la permanencia en posiciones relevantes en la élite política? El propósito de este trabajo es precisamente responder a estas preguntas evaluando y probando capitales clásicos de la sociología política como capital político, cultural y social. Los dos últimos capitales toman forma en este artículo en las variables referidas a recursos técnicos y capital político familiar, siendo la primera más representativa de la forma institucionalizada del capital cultural y la segunda una parte o una vía para adquirir capital social. El capital político se mide prácticamente de forma directa.

En la siguiente sección se realiza un breve recorrido sobre la teoría y el estudio de las élites, desde los clásicos hasta las temáticas de la literatura especializada más actual; se abordan temas como acceso, reclutamiento, circulación, permanencia y profesionalización de la política. En la segunda sección se aborda el estudio de las élites en Chile, particularmente el rol que jugaron los elencos elitarios en el proceso de transición política a fines de la década de 1980 y la importancia de la tecnocracia y la tecnopolítica. La tercera sección es un apartado metodológico que describe cómo se recogieron los datos para esta investigación, el procedimiento de muestreo realizado, la medición de las variables y las técnicas de análisis utilizadas. En la cuarta sección se presenta un análisis estadístico descriptivo donde se ven los orígenes sociales y los círculos en que se mueve el grupo estudiado; este apartado tiene un importante valor pues muestra los lugares de socialización de esta élite. La quinta sección presenta los resultados del análisis estadístico mediante regresiones logísticas binarias y un Análisis Comparado Cualitativo (QCA). Finalmente se presentan las conclusiones de la investigación. 


\section{La teoría y el estudio de las élites}

El desarrollo de la teoría de élites transitó desde las teorías clásicas de Pareto, Mosca y Michels, a comienzos del siglo pasado, hacia la controversia entre las tradiciones unitaria y pluralista. Aquella controversia se basaba en el debate entre quienes sostenían que las sociedades occidentales se regían por élites dominantes que controlaban los principales mecanismos de poder, frente a quienes señalaban la existencia de una pluralidad de élites que no concentraban el poder. La escuela pluralista fue impulsada, de acuerdo a Joignant (2009, 2011a), por Dahl, Schumpeter, Sartori, y otros; mientras que el principal teórico de la tradición unitaria fue Mills (1956/2000), quien acuñó el conocido concepto de élite de poder.

En las últimas décadas la literatura especializada se ha centrado en el rol que juegan las élites en los procesos de transición democrática y en las negociaciones que dichos procesos implican (Higley \& Burton, 1989; Higley \& Gunther, 1992; Higley \& Pakulski, 1992; Neuhouser, 1992, 1998). Por otra parte, actualmente el foco de estudio se encuentra en las características de élites nacionales, su cohesión, nivel de integración y consenso (Gulbrandsen, 2005, 2012; Gulbrandsen \& Engelstad, 2005; Pakulski, 2012). Sin desmedro de lo anterior, existe una serie de conceptos clásicos de la teoría de élites sobre los que aún es importante reflexionar. Estos conceptos son acceso, reclutamiento, circulación, permanencia y profesionalización.

El acceso a posiciones relevantes en la élite se encuentra determinado por el reclutamiento, concepto central en la teoría de élites. El reclutamiento fue descrito por Putnam (1976) como aquel proceso que conlleva a una selección de ciudadanos -entre varios millones- con suficiente motivación y socialmente favorecidos para alcanzar posiciones relevantes. De acuerdo a Uriarte (2002), el haber nacido en ciudades, ser hombre y haber estudiado en universidades prestigiosas son factores preponderantes que permiten alcanzar posiciones relevantes en la élite política. En esta misma línea, Ai Camp $(1995,2002,2006)$ señala, en sus análisis sobre la élite mexicana, que el lugar de residencia, la familia y los estudios realizados resultan centrales para la socialización de la élite. En las élites mexicanas, como en muchos otros países, las credenciales académicas son tremendamente importantes y sucede algo similar a lo que pasa en el caso chileno: buena parte de los líderes más importantes fueron educados en el extranjero, particularmente en Estados Unidos. 
El estudio del reclutamiento y sus redes permite entender las formas de reproducción de la élite (ver Bourdieu, 1986; Dogan, 1999; Offerlé, 1984/2004). Para Bourdieu (1986) es fundamental estudiar la especialización de los agentes políticos, así como el reclutamiento político y social, pues las élites se comprenden desde la especificidad de su campo y desde las relaciones existentes entre distintos campos (político, cultural, económico). En este sentido, estudiar la reconversión transversal de ciertos tipos de capitales resulta tan importante como estudiar la acumulación de distintos recursos y capitales $^{2}$. También resulta muy importante mirar los círculos sociales y los lugares de socialización en que se mueven los actores que son parte de la élite.

Otro concepto central es el de circulación, el cual se vincula estrechamente con las trayectorias individuales de cada actor. Con respecto a los patrones de circulación y trayectorias en puestos políticos, Marenco y Serna (2007) identificaron dos que resultan claves: carreras basadas en prestigio personal, familiar, fortuna, o educación, que por lo general tienen un carácter más bien discontinuo; y carreras políticas profesionales basadas en una fuerte experiencia partidaria y electoral. La circulación alta facilita la renovación de las élites políticas, además se puede considerar un símbolo de correcto funcionamiento democrático. Por otra parte, la circulación baja es directamente proporcional a una baja profesionalización de la actividad política, por lo cual la continuidad de la élite implica una especie de "curva de aprendizaje". En esta línea, la permanencia de agentes en posiciones institucionales puede ser considerada como una profesionalización si se toma el término como la posibilidad de realizar una carrera en el Estado, convirtiendo dicha actividad en una profesión, es decir, una actividad que genera conocimientos especializados. Asimismo, la circulación está asociada, de acuerdo a Putnam (1976), a períodos de crisis y estabilidad: durante los primeros hay una mayor circulación y recambio; en los segundos hay mayor permanencia.

La profesionalización se encuentra ligada al fenómeno de la permanencia, el cual a su vez se encuentra asociado al fenómeno de la circulación como se ha señalado. Muchas veces la permanencia pone en jaque la circulación de la élite e implica menores niveles de renovación política. Al respecto es importante señalar que es

2 Una reconversión transversal de ciertos tipos de capitales permite, por ejemplo, pasar del campo social al político. Esto desde la teoría de las élites es comprendido como reclutamiento social, el cual puede ser por: (a) osmosis, debido a la ocupación de un estatus socio-económico particularmente elevado; (b) predisposición a la actividad política, ligada al desempeño profesional que genera dicha situación (abogados, cientistas sociales, economistas, etc.); y (c) absorción de la sociedad civil, lo cual se da tradicionalmente en el caso de los representantes sindicales -como también en el caso de algunos dirigentes universitarios- (Dogan, 1999). 
posible entender la permanencia como una profesionalización sólo si ésta se refiere a la ocupación prolongada de posiciones institucionales en el Estado o en el campo político en general, y no a una profesionalización de "corte técnico".

Una mayor permanencia debiese generar una baja circulación, pero aquello no siempre sucede. La carrera de un actor en el gobierno no termina cuando deja un cargo determinado, pues muchas veces se mueve hacia otros cargos dentro del ejecutivo o migra hacia el parlamento (Blondel \& Müller-Rommel, 1997, 2007) -lo que se podría denominar movimiento entre esferas-. Esto genera circulación y a la vez genera permanencia, ya que el actor deja un determinado cargo sin dejar el campo político. A pesar de lo anterior, generalmente el fenómeno de la permanencia sí está asociado a una baja renovación producto de un cierre social.

Un cierre social es el establecimiento de una frontera, similar a la frontera señalada por Parkin (1984) con respecto a las clases sociales en las sociedades contemporáneas. Aguilar (2011) señaló que operan tres tipos de fronteras en la élite: (a) una frontera económica; (b) una frontera cultural en la línea de lo que Parkin (1984) denominó como monopolio en el acceso a credenciales académicas; y (c) una frontera moral, referida a fundamentos de carácter normativo y estilos de vida. "Estos tres tipos de fronteras que demarcan y enmarcan a la elite se corresponden con lo que otros autores [Bourdieu (1986)] han identificado como capital económico, capital cultural y capital simbólico" (Aguilar, 2011: 207).

En definitiva, mayor permanencia suele implicar menor circulación y más estabilidad política. En consecuencia, menor circulación implica menor renovación, mayor profesionalización y la generación de un cierre social que hace que el acceso a la élite política sea más limitado. Resulta complejo entonces combinar estabilidad y renovación política.

\section{El estudio de las élites en Chile}

\section{1 Élites, transición política y democratización}

El desarrollo de las élites en Chile se explica en buena parte por el proceso de transición y democratización post régimen autoritario. Las características de estos procesos han sido abordadas ampliamente por autores como Garretón (1997, 1999), Godoy (1999), Tironi y Agüero (1999), Valenzuela (1999), Huneeus (2005), Siavelis (2009), entre otros (ver Garretón, 2005; Garretón \& Garretón, 2010). Estos autores señalaron la existencia de enclaves autoritarios, describieron el carácter 
pactado de la transición, debatieron con respecto a la generación (o no) del clivaje autoritarismo-democracia y abordaron la existencia de enclaves de transición. El carácter pactado del proceso de transición resulta particularmente interesante, pues ratifica la importancia del rol de las élites en el establecimiento de regímenes democráticos, donde independiente del tipo de autoritarismo y los lapsos de inestabilidad, finalmente la consolidación democrática requirió de un pacto entre las élites (Higley \& Gunther, 1992; Mainwaring, 2013).

Más allá de los debates en torno al proceso de transición política, el carácter pactado de la transición chilena y la idea del congelamiento del sistema de partidos ${ }^{3}$, resultan conceptos centrales para entender el desarrollo de las élites políticas en Chile durante las últimas dos décadas. A estos conceptos hay que sumar la idea de la democracia de los consensos como lógica imperante en la transición y factor de éxito para el caso del presidencialismo chileno (Huneeus, 2005). Con todos estos factores se puede formar una tríada que se asocia al arreglo constitucional de la transición, tríada que en el fondo no solo define dicho proceso, sino que además se erige como un conjunto de características y determinantes socio-culturales de la ("no tan") nueva élite (Delamaza, 2010). En definitiva, el proceso de redemocratización condicionó los rasgos principales de la reconstrucción del campo político en la década de 1980, ofreciendo a distintos actores oportunidades de diferenciar trayectorias dependiendo de su posición. Además se abrió un amplio espacio en el aparato público que fue ocupado por militantes, simpatizantes y adherentes de la Concertación, coalición que entrenó buena parte de sus cuadros en la sociedad civil (Delamaza, 2010).

\subsection{La importancia de la tecnocracia y la tecnopolítica}

El interés por la tecnocracia y los tecnócratas ha dominado buena parte del estudio de las élites políticas en Chile. En esta línea, existen una serie de trabajos que resultan centrales para comprender el desarrollo de la élite política chilena durante las últimas décadas. En primer lugar se encuentran los trabajos de Silva (1991, 1997, 2006, 2009, 2011), Delamaza (2010, 2011), y Dávila (2011), los cuales abordaron el fenómeno tecnocrático en profundidad. Adicionalmente es absolutamente central el amplio trabajo teórico y empírico realizado por Joignant (2009, 2011a, 2011b, 2011c, 2011d) y Joignant, Perelló, y Torres (2012).

El congelamiento del sistema de partidos sufre posteriormente un proceso de descongelamiento con la recuperación democrática. Esto tuvo como consecuencia el resurgimiento de antiguos liderazgos (Tironi \& Agüero, 1999). 
De acuerdo a Silva $(2009,2011)$, el período comprendido entre los años 1990 y 2010 se caracterizó por la existencia de una influyente élite tecnocrática ${ }^{4}$, la cual estuvo compuesta por profesionales jóvenes con estudios de postgrado en el extranjero, principalmente en universidades norteamericanas. Aquella élite tecnocrática tuvo la oportunidad de protagonizar diversas reformas políticas. Esta tecnocracia mantuvo cierta distancia de la actividad política y una pugna creciente con la clase política tradicional, la cual con el tiempo creció, particularmente a partir del gobierno de Eduardo Frei Ruiz-Tagle (1994-2000), alcanzando niveles sin precedentes durante el gobierno de Michelle Bachelet (2006-2010). La élite tecnocrática tuvo como contexto el empate político o equilibrio de fuerzas que se dio en el marco de la transición política. Este empate implicó un poderoso incentivo para la adopción de fórmulas tecnocráticas, las cuales tomaron forma durante el gobierno de Patricio Aylwin (1990-1994) a través de lo que Silva (2009) denominó partido transversal 5 .

Para Delamaza (2011), la reproducción de la élite política chilena durante los últimos 20 años se asoció a dos situaciones: la existencia de lo que denominó elitismo democrático; y la expansión de la tecnopolítica. El elitismo democrático se asoció a la existencia de restricciones y pactos que dificultaron el acceso a posiciones de poder, es decir, el acceso a la élite política. Por otra parte, la tecnopolítica se expandió por el incremento de legitimidad del liderazgo de las personas que poseían una gran cantidad de recursos técnicos. En definitiva, existió una élite democrática durante la década de 1980, la cual posteriormente se convirtió en una élite tecnocrática que permaneció en el aparato estatal en las últimas décadas.

Mediante un estudio de trayectorias de funcionarios del poder ejecutivo (gobierno central), Delamaza (2010) advirtió la existencia de una pauta poco abierta y de escasa renovación. El estudio se centró básicamente en un análisis de trayectorias de funcionarios que asumieron cargos en las áreas políticas y sociales durante la transición y dio cuenta de que la Concertación privilegió la experiencia política para las posiciones relevantes, mientras que para las posiciones relativas a gestión

4 La influencia de la tecnocracia no es un fenómeno nuevo en Chile, se puede advertir desde los Chicago Boys e incluso se remonta a la creación de la Corporación de Fomento de la Producción (CORFO) (ver Silva, 2011; Dávila, 2011). Sin embargo, es importante señalar que no todos los países muestran una hegemonía tan clara del fenómeno tecnocrático y de agentes especializados como los economistas. En países como Estados Unidos, Filipinas, India, Corea e Indonesia, resulta importante la robustez de otras disciplinas que rivalizan con quienes promueven o representan el concepto tecnocrático (ver Dézalay \& Garth, 2002, 2006, 2008; Joignant, 2009, 2011a).

5 De acuerdo a Joignant (2011c) el término partido transversal también lo utilizó Camou (1997) para definir a los agentes catalizadores de consensos. 
técnica y de apoyo privilegió la experiencia o conocimientos en el área específica. En base a los datos analizados Delamaza identificó un vínculo entre la participación de los actores en organizaciones de la sociedad civil y el ingreso al gobierno.

El trabajo de Dávila (2011) estudió el rol de los tecnócratas durante los cuatro gobiernos de la Concertación y en el primer gabinete de Sebastián Piñera. Señaló que es posible distinguir perfiles (trayectorias) entre políticos y tecnócratas. Además advirtió una creciente tendencia a criticar la influencia desmedida de los tecnócratas en el gobierno y en los procesos de toma de decisiones sobre asuntos públicos, situación que se vincula a una tensión entre representación y calidad, pues los tecnócratas basan su influencia en su experticia, sin embargo, no cumplen con el principio de representación; es así como una tecnocracia influyente podría suponer una democracia representativa un tanto debilitada (ver Brooks, Stasiak, \& Zyro, 2013).

El fenómeno de la tecnocracia parece ser fundamental para el desarrollo de la élite política chilena, sin embargo, existe un agente distinto y a la vez similar al tecnócrata: el technopol. Este concepto, acuñado por Williamson (1994) y posteriormente popularizado por Domínguez (1996), se refiere a un actor que presenta elevados recursos técnicos y políticos, hecho que lo distancia de los clásicos tecnócratas. Si bien el concepto technopol ha sido abordado y utilizado por diversos autores, es Joignant (2011b, 2011c, 2011d) quien realiza un uso extensivo y sistemático del concepto para el caso chileno, incluyéndolo en su tipología de agentes. Además han sido los trabajos de Joignant los que han logrado ofrecer una mayor caracterización de agentes pertenecientes a la élite política chilena, poniendo un especial foco en lo referente al estudio de las élites gubernamentales.

De este modo, el estudio de las élites gubernamentales es llevado a cabo mediante una sociología de capitales de los agentes, cuyas variaciones $\mathrm{y}$ diferencias en sus componentes permiten dar cuenta de las bases políticas y los fundamentos sociales del poder que fue detentado por esta población de agentes poderosos (Joignant, 2011c: 50).

Al analizar posiciones de ministros y subsecretarios mediante encuestas, Joignant (2011b, 2011c) ha obtenido altas tasas de respuesta (entre un 50 y un 60\%). Por otra parte, la tipología que ofrece contempla tres grupos de agentes: tecnócratas, dirigentes de partido y technopols. Cada grupo de agentes presenta estructuras de capital específicas; en esta línea recientemente Joignant et al. (2012) distinguieron nueves especies de capitales políticos: (a) capital familiar, referido a una herencia de tradición política; (b) capital universitario, generado por la participación en organizaciones y movimientos estudiantiles; (c) capital político militante, referido a una participación 
en esferas partidistas sin ocupar necesariamente posiciones de privilegio dentro del partido; (d) capital político oligárquico, generado por la adquisición de experiencia en trayectorias militantes cortas que desembocan en cargos de primera línea partidaria; (e) capital tecnocrático pragmático, referente a la posesión de credenciales académicas prestigiosas acompañadas de independencia política; (f) capital tecnocrático político, el cual a diferencia del pragmático sí verifica una militancia política; (g) capital tecnopolítico (technopolitico), referido a la acumulación de recursos técnicos e importante capital político; (h) capital de notoriedad, consistente en recursos adquiridos fuera del campo político, particularmente en profesiones mediáticas; e (i) capital carismático, es decir, poseer una gran personalidad y liderazgo notable.

Además de sus tipologías de agentes y capitales, Joignant (2011b, 2011c, 2011d) describió a un reducido grupo de personas que responden a un perfil definido, un círculo íntimo de la Concertación ${ }^{6}$, compuesto precisamente por aquellos technopols que potencian un liderazgo colectivo y que conforman un grupo específico de agentes que poseen una combinación particular de recursos técnicos y políticos, lo que les permitió acceder a posiciones relevantes en el gobierno durante la década de 1990. Aquel círculo intimo ejerció un liderazgo colectivo y transversal y tuvo una gran influencia en los ámbitos gubernamental, parlamentario y partidario; situación que explica la gran estabilidad política vivida durante el período de transición y en los primeros gobiernos de la Concertación, aunque también da cuenta de cómo un reducido grupo de agentes, que presentan una configuración particular de recursos (estructura de capital), accede a posiciones relevantes y permanece en ellas de forma prolongada.

\section{Evaluando factores de acceso y permanencia en la élite política gubernamental}

Este trabajo busca analizar los factores que afectan el acceso y la permanencia de la élite política gubernamental en Chile para el período 1990-2010.Lo anterior implica: (a) caracterizar la élite política gubernamental chilena en el período estudiado; (b) asociar factores al acceso; y (c) evidenciar y probar factores de permanencia. Se trabaja particularmente con la élite política gubernamental, la cual se considera una sub-élite de la élite política, la que a su vez se encuentra compuesta por otras sub-élites como la parlamentaria, partidaria, e incluso burocrática. Estas sub-élites se entremezclan y superponen.

6 El concepto de círculo íntimo es similar al concepto de núcleo elitario y se recoge del trabajo de Kadushin (1995), quien realizó un análisis de los antecedentes y relaciones de amistad de la élite financiera francesa. 
Se trabaja con un grupo de variables entre las que se considera la militancia política de los actores, su acumulación de recursos técnicos y la verificación de capital político familiar. La hipótesis principal de este trabajo es que en Chile, la militancia política destacada $\left(\mathrm{X}_{1}\right)$, la posesión de recursos técnicos sobresalientes $\left(\mathrm{X}_{2}\right)$, y la posesión de capital político familiar $\left(\mathrm{X}_{3}\right)$, permiten acceso $(\mathrm{Y} \alpha)$ y/o permanencia (Y) a la élite política gubernamental (posiciones institucionales relevantes en el ejecutivo) durante el período 1990-2010.

La metodología utilizada contempla: (a) un análisis estadístico descriptivo para caracterizar la muestra del estudio; (b) un análisis estadístico (regresión logística binaria) para evaluar los factores de acceso y permanencia; y (c) un Análisis Comparado Cualitativo (Qualitative Comparative Analysis, QCA) (ver Ragin, 1987, 2000, 2006, 2013; Vaisey, 2009) para probar y evaluar factores de acceso y permanencia.

El uso de QCA permite someter a prueba las variables independientes para determinar la condición de causalidad que poseen con respecto a la variable dependiente. Se trabaja específicamente con el conjunto clásico o crisp-set QCA (csQCA) y no con conjuntos difusos o fuzzy-set QCA (fsQCA). QCA es una poderosa herramienta para probar teorías y variantes a éstas (Rihoux, 2006; Goertz \& Mahoney, 2005). Si bien se tiende a pensar que el uso de QCA está estrictamente limitado a investigaciones con poca cantidad de casos (small-N), aquello es incorrecto (ver Grofman \& Schneider, 2009; Ragin \& Fiss, 2008). Rihoux, Álamos-Concha, Bol, Marx y Rezsöhazy (2013) distinguen tres categorías de estudios con QCA de acuerdo al número de casos: (a) investigaciones con small- $N$, que corresponden a trabajos con menos de diez casos; (b) investigaciones con medium- $N$, que presentan entre diez y 50 casos; y (c) investigaciones con large- $N$, que corresponden a conjuntos de datos con más de 50 casos. De acuerdo a Rihoux et al. (2013) las investigaciones publicadas con csQCA y fsQCA no presentan diferencias significativas en cuanto al número de casos y al menos un $12 \%$ de los estudios se realizan con conjuntos de datos de large- $N$. Cabe señalar que al menos un 6\% de los estudios con gran cantidad de casos se concentran en el tramo entre 100 y 199 casos, lo cual corresponde a poco más de 18 publicaciones de 313 artículos en revistas con revisión de pares ${ }^{7}$.

Se estima que a diciembre de 2011 existían más de 750 trabajos que usaban QCA. Esta cifra contempla artículos de revistas, libros y capítulos, publicaciones electrónicas (Rihoux et al., 2013). 


\subsection{Censando a la élite política}

Se considera que explicar el acceso $(\mathrm{Y} \alpha)$ no es lo mismo que explicar la permanencia, ya sea ésta considerada en años (a) o como permanencia destacada (Y). En el primer fenómeno influyen al menos dos tipos de determinantes: factores individuales, tales como recursos y capitales de cada actor (estructuras de capital); y factores institucionales que se consideran como variables constantes en esta investigación, tales como la proporcionalidad en los nombramientos en el ejecutivo respecto al peso electoral de cada partido de la coalición, particularidades del sistema electoral, etc. En la permanencia influyen, por otra parte, un tercer tipo de determinantes donde se pueden agrupar la gestión o desempeño del actor durante su tiempo en el ejecutivo, la evaluación del gobierno, la evaluación del propio actor en las encuestas de opinión -en los casos que corresponda-, entre otras. Estos factores no han sido considerados en la presente investigación. La decisión de complementar el análisis estadístico con csQCA se funda en el supuesto de que con la información recabada resulta complejo generar un modelo estadístico que arroje claridad sobre el fenómeno de la permanencia, sin embargo, se supone posible generar un modelo sencillo para analizar acceso.

\subsubsection{Procedimiento de muestreo}

Se identifican un total de diez posiciones institucionales relevantes, las cuales fueron ocupadas por 1.465 actores durante el período 1990-2010. Se considera a personas que ocuparon al menos un semestre una de las siguientes posiciones: (a) Presidente de la República; (b) ministro; (c) subsecretario; (d) jefe de división; (e) jefe de gabinete, (f) director de ciertos servicios y organismos ${ }^{8}$; (g) diputado; (h) senador; e (i) miembro de mesa directiva de partido político (presidente, vice-presidente y secretario general o nacional).

Se identifica el núcleo elitario con el fin de aplicar una encuesta de más de 70 preguntas que abordan trayectoria personal, antecedentes familiares, profesionales, trayectoria política, vinculaciones, percepciones y caracterización en general. El núcleo elitario asciende a 590 casos que se seleccionan bajo criterios específicos?

8 Presidente del Banco Central, del Consejo Nacional de la Televisión (CNTV), superintendente, director ejecutivo de Televisión Nacional de Chile (TVN), vice-presidente ejecutivo de la Corporación Nacional del Cobre (CODELCO) y de la Corporación de Fomento (CORFO), director ejecutivo del Fondo Nacional de Salud (FONASA).

9 Los criterios de selección fueron los siguientes: (a) todos los actores que se desempeñaron como Presidente de la República; (b) todos los actores que se desempeñaron como ministro; (c) todos 
El procedimiento a seguir consiste en censar el núcleo elitario, no se determinan mecanismos de reemplazo. Se logra recopilar la información de 386 casos $(N=386)$, tal como se detalla en la Tabla 1.

Tabla 1

Composición de los casos recabados del núcleo elitario $(N=386)$

\begin{tabular}{|l|c|c|}
\hline Cargos & $\begin{array}{c}\text { Número de } \\
\text { entrevistados }\end{array}$ & Porcentaje \\
\hline Presidentes de la República & 3 & $0,78 \%$ \\
\hline Ministros & 106 & $27,46 \%$ \\
\hline Senadores & 28 & $7,25 \%$ \\
\hline Diputados & 123 & $31,86 \%$ \\
\hline Subsecretarios & 37 & $9,59 \%$ \\
\hline Intendentes & 4 & $1,04 \%$ \\
\hline $\begin{array}{l}\text { Presidentes Banco Central, } \\
\text { superintendentes, directores de } \\
\text { empresas públicas }\end{array}$ & 22 & $5,70 \%$ \\
\hline Jefes de gabinete y/o división & 67 & $14,77 \%$ \\
\hline $\begin{array}{l}\text { Miembros de las mesas directivas de los } \\
\text { partidos }\end{array}$ & 386 & $1,55 \%$ \\
\hline Total & $60 \%$ \\
\hline
\end{tabular}

Nota. Cada actor es tipificado de acuerdo al máximo cargo que llegó a ocupar a lo largo de su trayectoria. El porcentaje indicado da cuenta de la composición de muestra en base a la tasa de respuesta $(N=386)$ y no con respecto al total del núcleo elitario $(N=590)$. Fuente: Elaboración propia, adaptada de Joignant et al. (2012:17)

los actores que se desempeñaron como subsecretario; (d) todos los diputados que alcanzaron dos o más mandatos; (e) todos los senadores que alcanzaron dos o más mandatos; (f) todos los actores que fueron electos diputados y senadores, aunque hayan cumplido sólo un período en cada cargo (es decir, fueron electos como diputados y luego como senadores); (g) todos los actores que fueron presidente de partido político con representación parlamentaria durante el período; (h) todos los actores miembros de mesas directivas de partidos con representación parlamentaria en el período y que ejercieron funciones durante tres años; (i) todos los jefes de división que permanecieron en su cargo por más de un período presidencial; (j) todos los actores que se desempeñaron como presidentes o gerentes generales de un grupo de empresas públicas (TVN, CORFO, CODELCO, etc.); (k) todos los directores de presupuesto; y (l) una combinación de dos o más de estos criterios. 


\subsubsection{Tamaño y precisión de la muestra}

La información recopilada sobre el núcleo elitario alcanza una tasa de respuesta de un $65,42 \%(N=386)$, sin embargo, tal como señalan Joignant et al. (2012), esta tasa puede elevarse si se excluyen del cálculo los casos de individuos fallecidos, así alcanza un $68,31 \%$. La tasa de respuesta es bastante buena si se compara con otros estudios similares que alcanzaron cifras entre el 50 y el 60\% (ver Joignant, 2011b). Por otra parte, el nivel de representatividad de la muestra es bastante alto, sobre todo para los cargos más importantes. Si se toma el caso de los ministros, por ejemplo, esta muestra recoge al 62,35\% de quienes fueron nombrados entre 1990 y 2010 (González Bustamante, 2013).

Sobre la información recopilada del núcleo elitario $(N=386)$, se procede a seleccionar una muestra que representa a la élite política gubernamental para el período estudiado, esto en relación a la ocupación de posiciones institucionales consideradas como las más relevantes en el ejecutivo ${ }^{10}$. Es así como se obtiene una muestra con casos de agentes que ocuparon al menos uno de los cargos considerados como más relevantes en el ejecutivo entre marzo de 1990 y marzo de $2010(n=199)^{11}$. Esta es la muestra que representa a la élite política gubernamental para el período estudiado.

\subsubsection{Diseño de investigación, medidas y variables}

La operacionalización de variables se basa en la tipificación de especies y subespecies de capital propuesta por Joignant et al. (2012). Se incorporan una serie de variables independientes alternativas que recogen factores que también podrían influir en las variables dependientes. Estas variables alternativas se incorporan en el análisis de forma auxiliar (ver Tabla 2). La operacionalización de variables se realiza mayoritariamente en base a la encuesta realizada al núcleo elitario $(N=386)$, sin embargo, se recolecta información adicional en base a revisión de antecedentes biográficos y verificación de trayectorias.

10 Se consideran los siguientes cargos como lo más relevantes: (a) Presidente de la República; (b) ministro; (c) subsecretario; (d) embajador; (e) jefe de servicio; (f) intendente; (g) director o gerente de empresa pública; y (h) superintendente.

11 En un principio se detectaron 225 casos, sin embargo, se verificaron la totalidad de las trayectorias a través de recopilación de información biográfica adicional. Veintiséis casos fueron excluidos por corresponder a agentes que ocuparon cargos relevantes fuera del período estudiado o corresponder a casos cuya trayectoria fue imposible de verificar con información pública. 
Tabla 2

Síntesis y operacionalización de variables principales y alternativas

\begin{tabular}{|c|c|c|}
\hline Variable & Posible relación & Operacionalización \\
\hline \multicolumn{3}{|c|}{ Variables independientes principales } \\
\hline $\mathrm{X}_{1}$ & $\begin{array}{c}\text { La militancia política destacada } \\
\text { permite (o no) permanencia } \\
\text { destacada (o acceso) a la élite política } \\
\text { gubernamental }\end{array}$ & $\begin{array}{l}\text { En base a preguntas sobre } \\
\text { militancia política }\end{array}$ \\
\hline $\mathrm{X}_{2}$ & $\begin{array}{l}\text { La posesión de recursos técnicos } \\
\text { sobresalientes permite (o no) } \\
\text { permanencia destacada (o acceso) a la } \\
\text { élite política gubernamental }\end{array}$ & $\begin{array}{c}\text { En base a preguntas donde se recoge } \\
\text { información sobre estudios de } \\
\text { postgrado, dónde fueron realizados, } \\
\text { grado académico obtenido, } \\
\text { disciplina, etc. }\end{array}$ \\
\hline$X_{3}$ & $\begin{array}{l}\text { La posesión de capital político } \\
\text { familiar permite (o no) permanencia } \\
\text { destacada (o acceso) a la élite política } \\
\text { gubernamental }\end{array}$ & $\begin{array}{c}\text { En base a preguntas donde se recoge } \\
\text { información sobre si el padre o la } \\
\text { madre ocuparon alguna posición } \\
\text { relevante en el Estado }\end{array}$ \\
\hline \multicolumn{3}{|c|}{ Variables dependientes } \\
\hline $\mathrm{Y} \alpha$ & $\begin{array}{c}\text { Acceso a la élite política } \\
\text { gubernamental }\end{array}$ & $\begin{array}{c}\text { En base a preguntas donde se recoge } \\
\text { información sobre trayectoria pública } \\
\text { y/o privada entre } 1990 \text { y } 2010\end{array}$ \\
\hline $\mathrm{Y}$ & $\begin{array}{l}\text { Permanencia destacada en la élite } \\
\text { política gubernamental }\end{array}$ & $\begin{array}{l}\text { En base a preguntas donde se recoge } \\
\text { información sobre trayectoria pública } \\
\text { y/o privada entre } 1990 \text { y } 2010 . \text { Se } \\
\text { complementa con recolección de } \\
\text { información adicional y verificación } \\
\text { de trayectorias }\end{array}$ \\
\hline (a) & $\begin{array}{l}\text { Años de permanencia en la élite } \\
\text { política gubernamental } \\
\text { (años en el ejecutivo) }\end{array}$ & $\begin{array}{c}\text { En base a recopilación de } \\
\text { antecedentes, recolección de } \\
\text { información adicional y verificación } \\
\text { de trayectorias }\end{array}$ \\
\hline \multicolumn{3}{|c|}{ Variables independientes alternativas } \\
\hline $\mathrm{X} 1 .{ }_{2}$ & $\begin{array}{c}\text { El capital político universitario } \\
\text { permite (o no) permanencia } \\
\text { destacada (o acceso) a la élite política } \\
\text { gubernamental }\end{array}$ & $\begin{array}{l}\text { En base a preguntas donde se recoge } \\
\text { información sobre participación en } \\
\text { organizaciones estudiantiles }\end{array}$ \\
\hline $\mathrm{X} 3 ._{2}$ & $\begin{array}{l}\text { La militancia política de los padres } \\
\text { permite (o no) permanencia } \\
\text { destacada (o acceso) a la élite política } \\
\text { gubernamental }\end{array}$ & $\begin{array}{c}\text { En base a preguntas sobre militancia } \\
\text { política de los padres }\end{array}$ \\
\hline
\end{tabular}




\begin{tabular}{|c|c|c|}
\hline Variable & Posible relación & Operacionalización \\
\hline $\mathrm{X}_{4}$ & $\begin{array}{l}\text { El reconocimiento de nombramiento } \\
\text { y/o elección determinada por } \\
\text { trayectoria profesional previa } \\
\text { permite (o no) permanencia } \\
\text { destacada (o acceso) a la élite política } \\
\text { gubernamental }\end{array}$ & $\begin{array}{c}\text { En base a pregunta sobre } \\
\text { identificación de elementos } \\
\text { determinantes en el nombramiento } \\
\text { del primer cargo público }\end{array}$ \\
\hline $\mathrm{X}_{5}$ & $\begin{array}{l}\text { Pertenencia a centros de estudios } \\
\text { o think tanks permite (o no) } \\
\text { permanencia destacada (o acceso) a la } \\
\text { élite política gubernamental }\end{array}$ & $\begin{array}{c}\text { En base a pregunta sobre pertenencia } \\
\text { a centros de estudio y el nivel de } \\
\text { participación }\end{array}$ \\
\hline
\end{tabular}

Fuente: Elaboración propia

Es importante tener en cuenta que la muestra que representa a la élite política gubernamental $(n=199)$ está compuesta por actores que alcanzaron al menos una vez una de las posiciones que se consideran como las más relevantes en el ejecutivo. Sin embargo, evidentemente, alcanzar una vez una posición relevante no implica una permanencia destacada: no es lo mismo ser asesor 20 años que haber sido ministro durante cinco años. Mientras el primero presenta mayor cantidad de años, es decir, una permanencia prolongada, el segundo con solo cinco años presenta una permanencia destacada.

Por lo anterior, la permanencia destacada $(Y)$ se determina a través de un índice que se calcula en base a los años en el ejecutivo (a) por un factor específico, el cual depende de la importancia del cargo ocupado en dichos años (ver Tabla 3).

Tabla 3

Cálculo de la variable dependiente, permanencia destacada (Y)

\begin{tabular}{|l|c|}
\hline Cargo & Cálculo \\
\hline Presidente de la República & $\mathrm{Y}=\mathrm{a} \times \mathrm{x} 6$ \\
\hline Ministro & $\mathrm{Y}=\mathrm{a} \times \mathrm{x} 5$ \\
\hline Subsecretario & $\mathrm{Y}=\mathrm{a} \times \mathrm{x}$ \\
\hline Jefe de servicio, embajador, director empresa pública, superintendente & $\mathrm{Y}=\mathrm{a} \times \mathrm{x} 3$ \\
\hline Intendentes, miembro directorio empresa pública & $\mathrm{Y}=\mathrm{a} \times 2$ \\
\hline $\begin{array}{l}\text { Otros cargos considerados dentro de los criterios de selección del núcleo } \\
\text { elitario }\end{array}$ & $\mathrm{Y}=\mathrm{a} \times 1$ \\
\hline
\end{tabular}

Nota. Se incluyen cargos que no están considerados dentro de los más relevantes, pues hay actores que previamente a alcanzar un cargo relevante -e incluso de forma posterior- ocuparon cargos menos importantes. Para el caso de personas que ejercen dos cargos a la vez (biministro) se suman los cálculos respectivos.

Fuente: Elaboración propia 
La variable años de permanencia en el ejecutivo (a) presenta las siguientes características: valor mínimo de uno; valor máximo de 20; $M=9,35 ; \mathrm{y} M d n=8$. La moda del grupo se ubica en cuatro años. La distribución entre valores observados es normal: presenta una asimetría de ,431 y un valor de -,993 para curtosis.

La permanencia destacada $(\mathrm{Y})$ se obtiene mediante el índice de permanencia destacada, el cual tiene las siguientes características: valor mínimo de dos; valor máximo de 107; $M=27,11 ; y M d n=24$. La distribución no es normal pues presenta una asimetría y curtosis elevada (1,106 y 2,172 respectivamente) y la prueba de Kolmogorov-Smirnov falla $(K-S=, 032)$. Lo anterior se debe a que los dos valores máximos presentan cifras muy elevadas, sin embargo, al suprimir aquellos dos casos los datos presentan una distribución normal con una asimetría y curtosis más bajas (,626 y -,218 respectivamente), mientras que la media baja levemente $(M=26,44)$ y la mediana se mantiene, además la prueba de Kolmogorov-Smirnov presenta una significancia normal $(K-S=0,51)$.

En los análisis de datos con regresión logística binaria y csQCA no se excluyen los dos casos que presentan valores extremos para permanencia destacada $(\mathrm{Y})$, sin embargo, en el proceso de binarización (dicotomización) de la variable se considera como umbral de corte el valor justo sobre la mediana y no la media, así se evita influenciar la recodificación de las variables con valores no normales.

\subsubsection{Esquema de valores binarios}

Las variables independientes y dependientes se consideran de forma dicotómica, en este sentido, se mide ausencia o presencia de forma binaria, tanto en el modelo de regresión logística como en los análisis con csQCA (ver Tabla 4). Cabe señalar que QCA se basa en lógica binaria y Boolean algebra para maximizar el número de comparaciones que se pueden realizar sobre los casos de investigación. La lógica es determinista, no estadística o probabilística (ver Ragin, 2013; Rihoux, 2006; Rihoux \& Marx, 2013). 
Tabla 4

Esquema de valores binarios para las variables del estudio

\begin{tabular}{|c|c|c|c|}
\hline & Variable & Medición & $\begin{array}{l}\text { Valor } \\
\text { binario }\end{array}$ \\
\hline \multicolumn{4}{|c|}{ Variables independientes principales } \\
\hline \multirow{2}{*}{$\mathrm{X}_{1}$} & \multirow{2}{*}{$\begin{array}{l}\text { Militancia política } \\
\text { destacada }\end{array}$} & $\begin{array}{l}\text { Cargo directivo partidario a nivel } \\
\text { nacional o regional }\end{array}$ & 1 \\
\hline & & $\begin{array}{c}\text { Cargo directivo partidario a nivel local } \\
\text { o no ocupa cargo directivo }\end{array}$ & 0 \\
\hline \multirow[b]{2}{*}{$\mathrm{X}_{2}$} & \multirow{2}{*}{$\begin{array}{l}\text { Recursos técnicos } \\
\text { sobresalientes }\end{array}$} & $\begin{array}{l}\text { Posesión de un postgrado (Magíster o } \\
\text { Doctorado) o estudios de Doctorado }\end{array}$ & 1 \\
\hline & & $\begin{array}{c}\text { Estudios de Magíster sin terminar, título } \\
\text { universitario, estudios técnicos o } \\
\text { educación secundaria }\end{array}$ & 0 \\
\hline \multirow{2}{*}{$\mathrm{X}_{3}$} & \multirow{2}{*}{ Capital político familiar } & $\begin{array}{l}\text { Padre o madre ejerció cargo de primera línea } \\
\text { gubernamental o fue parlamentario }\end{array}$ & 1 \\
\hline & & $\begin{array}{l}\text { Otros cargos como jefe de servicio, jefe de } \\
\text { gabinete, embajador o ningún cargo }\end{array}$ & 0 \\
\hline \multicolumn{4}{|c|}{ Variables dependientes } \\
\hline \multirow{2}{*}{$Y \alpha$} & \multirow{2}{*}{$\begin{array}{c}\text { Acceso a la élite } \\
\text { política gubernamental }\end{array}$} & $\begin{array}{l}\text { Pertenece a la élite política gubernamental } \\
\qquad(n=199)\end{array}$ & 1 \\
\hline & & $\begin{array}{c}\text { Pertenece al núcleo elitario }(N=386) \text { y no a } \\
\text { la élite política gubernamental }(n=199)\end{array}$ & 0 \\
\hline \multirow{2}{*}{ Y } & \multirow{2}{*}{$\begin{array}{l}\text { Permanencia destacada } \\
\text { en la élite política } \\
\text { gubernamental }\end{array}$} & $\begin{array}{l}\text { Índice de permanencia destacada superior a } \\
\text { la } M d n \text { del conjunto }\end{array}$ & 1 \\
\hline & & $\begin{array}{l}\text { Índice de permanencia destacada igual o } \\
\text { inferior a la } M d n \text { del conjunto }\end{array}$ & 0 \\
\hline \multirow{2}{*}{ (a) } & \multirow{2}{*}{$\begin{array}{l}\text { Años de } \\
\text { permanencia en la élite } \\
\text { política gubernamental }\end{array}$} & $\begin{array}{l}\text { Cantidad de años en el ejecutivo superior a la } \\
\qquad M d n \text { del conjunto }\end{array}$ & 1 \\
\hline & & $\begin{array}{l}\text { Cantidad de años en el ejecutivo igual o } \\
\text { inferior a la } M d n \text { del conjunto }\end{array}$ & 0 \\
\hline \multicolumn{4}{|c|}{ Variables independientes alternativas } \\
\hline \multirow{2}{*}{$\mathrm{X} 1 .{ }_{2}$} & \multirow{2}{*}{$\begin{array}{l}\text { Capital político } \\
\text { universitario }\end{array}$} & $\begin{array}{l}\text { Ocupó cargo directivo en } \\
\text { organizaciones estudiantiles }\end{array}$ & 1 \\
\hline & & $\begin{array}{l}\text { No ocupó cargo directivo en } \\
\text { organizaciones estudiantiles }\end{array}$ & 0 \\
\hline \multirow[b]{2}{*}{$\mathrm{X} 3_{.2}$} & \multirow{2}{*}{$\begin{array}{l}\text { Militancia política de } \\
\text { los padres }\end{array}$} & Padre o madre presentan militancia política & 1 \\
\hline & & $\begin{array}{l}\text { Ni padre ni madre presentan } \\
\text { militancia política }\end{array}$ & 0 \\
\hline
\end{tabular}




\begin{tabular}{|c|c|c|c|}
\hline & Variable & Medición & $\begin{array}{l}\text { Valor } \\
\text { binario }\end{array}$ \\
\hline & Troustoris ar forion & $\begin{array}{c}\text { Identificación de trayectoria profesional } \\
\text { previa como determinante en } \\
\text { nombramiento o elección }\end{array}$ & 1 \\
\hline$\Lambda_{4}$ & 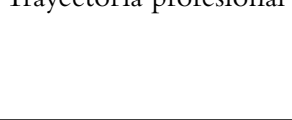 & $\begin{array}{c}\text { No identificación de trayectoria profesional } \\
\text { previa como determinante en } \\
\text { nombramiento o elección }\end{array}$ & 0 \\
\hline $\mathrm{Y}$ & Pertenencia a think & $\begin{array}{c}\text { Pertenencia a centros de estudios } \\
\text { o think tanks }\end{array}$ & 1 \\
\hline$\Lambda$ & tanks & $\begin{array}{l}\text { No pertenencia a centros de estudios } \\
\text { o think tanks }\end{array}$ & 0 \\
\hline
\end{tabular}

Nota. Los cargos de primera línea gubernamental se refieren a ministros y subsecretarios. El capital político universitario y la pertenencia a think tanks se considera en base a la participación del actor en dichas organizaciones antes de asumir su primer cargo público.

Fuente: Elaboración propia

\section{Análisis estadístico descriptivo del grupo}

\subsection{Género, religión, comuna, y grupos etarios}

La muestra que representa a la élite política gubernamental $(n=199)$ presenta en términos generales ciertas características homogéneas que se enmarcan en lo señalado por la teoría de élites: la mayoría de los actores son hombres (164 hombres y 35 mujeres); católicos (ver Tabla 5); y nacidos en la Región Metropolitana -siendo las tres comunas que presentan mayor cantidad de casos las siguientes: (a) Santiago (47 casos); (b) Las Condes (17 casos); y (c) Providencia (15 casos)-. Además la mayoría de los actores pertenecen a grupos etarios similares (ver Gráfico 1).

Tabla 5

Religión de la élite política gubernamental en Chile $(n=199)$

\begin{tabular}{|l|c|c|}
\hline Creencia religiosa & Número de casos & Porcentaje \\
\hline Católico & 96 & $48,24 \%$ \\
\hline Ateo o agnóstico & 86 & $43,22 \%$ \\
\hline Cristiano no católico & 5 & $2,51 \%$ \\
\hline Judío & 3 & $1,51 \%$ \\
\hline Budista & 1 & $0,50 \%$ \\
\hline Total & 191 & $95,98 \%$ \\
\hline
\end{tabular}

Nota. Se registran ocho casos de no respuesta, lo que equivale al 4,02\% de la muestra.

Fuente: Elaboración propia. 
Gráfico 1

Años de nacimiento de los actores de la élite política gubernamental $(n=199)$, con tendencia lineal

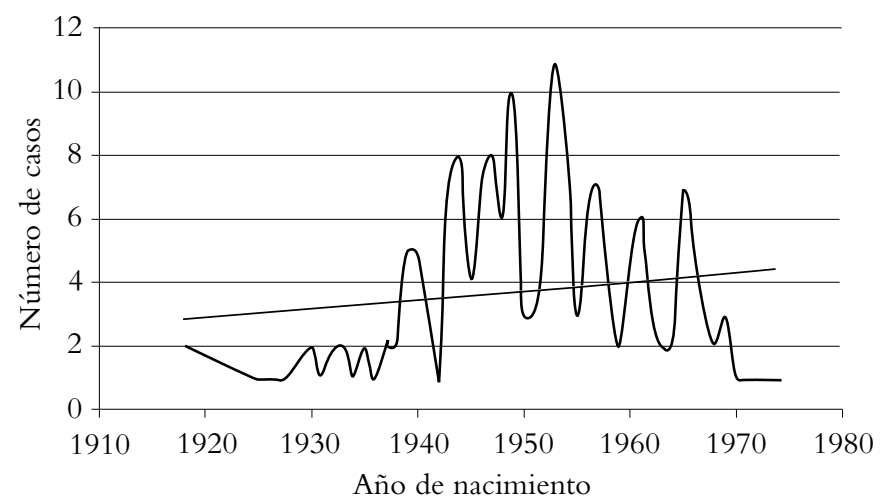

Gráfico 1. El rango de nacimiento de los actores oscila entre 1918 y 1974, $M=1951, M d n=$ 1951, la moda es 1953 (11 casos).Veinte casos se registran como perdidos de sistema.

Fuente: Elaboración propia

\subsection{Una élite ilustrada y "concentrada"}

El grupo está compuesto por actores que presentan lo que la teoría de campos y capitales denomina una gran cantidad de capital cultural institucionalizado, es decir, grandes cantidades de recursos técnicos. La mayoría posee educación universitaria completa y un número significativo presenta estudios de Magíster e incluso Doctorado como se puede apreciar en la Tabla 6.

Tabla 6

Nivel educacional alcanzado por actores de la élite política gubernamental $(n=199)$

\begin{tabular}{|l|c|c|}
\hline Nivel educacional alcanzado & Número de casos & Porcentaje \\
\hline Media & 1 & $0,50 \%$ \\
\hline Universitaria o técnica sin título & 13 & $6,53 \%$ \\
\hline Universitaria completa & 57 & $28,64 \%$ \\
\hline Estudios de postgrado & 30 & $15,08 \%$ \\
\hline Titulado de Magíster & 47 & $23,62 \%$ \\
\hline Candidato a Doctor & 12 & $6,03 \%$ \\
\hline Titulado de Doctor & 35 & $17,59 \%$ \\
\hline Total & 195 & $97,99 \%$ \\
\hline
\end{tabular}

Nota. Se registran cuatro casos de perdidos de sistema, lo que equivale al 2,01\% de la muestra. Fuente: Elaboración propia 
Se produce una "concentración" en la adquisición del capital cultural, pues un 30,15\% de los actores de la muestra estudiaron solo en cinco colegios: (a) Instituto Nacional; (b) Los Padres Franceses; (c) San Ignacio; (d) Alemán; y (e) Saint George. El resto estudió en colegios similares: prestigiosos, tradicionales y exclusivos. Asimismo, un $82,41 \%$ realizó sus estudios universitarios de pregrado en solo cuatro instituciones, donde destaca la Universidad de Chile con un 57,79\% y la Pontificia Universidad Católica de Chile con un 18,59\%. Las carreras más recurrentes son: (a) Derecho (68 casos); (b) Ingeniería Comercial (30 casos); y (c) Ingeniería (19 casos). Los postgrados se concentran de forma casi absoluta en las áreas de Ciencia Política y Economía.

\subsection{La militancia política como característica predominante}

El grupo presenta una alta tasa de militantismo, lo que eleva las posibilidades de que presenten capital político elevado. El $85,43 \%$ presenta una militancia política (170 casos), mientras el 7,03\% son independientes (14 casos), y un 7,54\% no poseen militancia (15 casos).

Cabe señalar que la diferencia entre actores independientes y sin militancia radica en que los últimos corresponden a personas que nunca han militado en un partido político. Los agentes independientes, por otra parte, son aquellos que al momento de la aplicación de la encuesta no verifican una militancia activa, pero que anteriormente militaron en uno o más partidos políticos. De los 15 casos que no presentan militancia, sólo dos declaran no tener ninguna simpatía política, el resto se declaran abiertamente simpatizantes de la Concertación o de alguno de sus partidos. En la Tabla 7 se presenta el detalle del grupo.

Tabla 7

Militancia de la élite política gubernamental en base al último partido $(n=199)$

\begin{tabular}{|l|c|c|}
\hline Militancia & $\begin{array}{c}\text { Número } \\
\text { de casos }\end{array}$ & Porcentaje \\
\hline Partido Regionalista de los Independientes (PRI) & 1 & $0,50 \%$ \\
\hline Partido Humanista (PH) & 1 & $0,50 \%$ \\
\hline Partido Comunista de Chile (PC) & 1 & $0,50 \%$ \\
\hline Otros & 2 & $1,00 \%$ \\
\hline Independiente (IND) & 14 & $7,04 \%$ \\
\hline Partido Radical Social Demócrata (PRSD) & 14 & $7,04 \%$ \\
\hline Sin militancia & 15 & $7,54 \%$ \\
\hline Partido Socialista de Chile (PS) & 34 & $17,08 \%$ \\
\hline Partido Por la Democracia (PPD) & 39 & $19,60 \%$ \\
\hline Partido Demócrata Cristiano (PDC) & 78 & $39,20 \%$ \\
\hline Total & 199 & $100 \%$ \\
\hline
\end{tabular}

Nota. La categoría otros corresponde a un entrevistado que no respondió y a un agente que consigno su pertenencia al Movimiento Amplio Social. Fuente: Elaboración propia 


\section{Análisis estadístico y Análisis Comparado Cualitativo (QCA)}

\subsection{Regresión logística binaria para acceso a la élite política gubernamental}

En el modelo se han utilizado las variables independientes principales y alternativas, además se ha considerado la variable de género binarizada en uno para los hombres y edad (al año 2010) como variable numérica. Para acceso (Y $\alpha$ ), las pruebas de ómnibus para los coeficientes del modelo presentan una significancia muy alta: $p=$ , $000 ; \chi^{2}=55,880$. El análisis bivariado arroja niveles de significancia estadística para las siguientes variables: $\mathrm{X}_{2}(p=, 000) ; \mathrm{X}_{4}(p=, 001) ; \mathrm{y} \mathrm{X}_{5}(p=, 000)$. Sin embargo, las variables que dentro del modelo presentan significancia son: género $(p=, 024)$; edad $(p=, 045) ; \mathrm{X}_{2}(p=, 000) ; \mathrm{y}_{5}(p=, 000)$. Esto sugiere que la edad y el género son estadísticamente relevantes dentro del modelo y que la identificación de la trayectoria profesional previa $\left(\mathrm{X}_{4}\right)$ presenta una relación espuria con respecto al acceso a la élite política gubernamental ( $\mathrm{Y} \alpha$ ). En definitiva, de acuerdo al modelo, lo importante para el acceso es ser hombre, haber nacido particularmente entre mediados de la década de 1940 y 1950 , poseer recursos técnicos sobresalientes $\left(\mathrm{X}_{2}\right)$ y pertenecer a centros de estudios o think tanks ligados a la Concertación $\left(\mathrm{X}_{5}\right)$.

\subsection{Regresión logística binaria para permanencia en la élite política gubernamental}

Si bien el modelo explica acceso ( $\mathrm{Y} \alpha$ ), no es capaz de explicar los años en el ejecutivo (a) considerando la variable binarizada justo sobre $M d n=8$. Para años en el ejecutivo (a) las pruebas de ómnibus presentan $n s: p=, 501 ; \chi^{2}=8,338$. El modelo sí explica permanencia destacada $(\mathrm{Y})$ con la variable binarizada justo sobre $M d n=24$; Las pruebas de ómnibus para los coeficientes del modelo presentan significancia estadística: $p=, 025 ; \chi^{2}=19,044$. Sin embargo, si bien varias variables presentan significancia fuera de la ecuación, todas presentan $n s$ dentro del modelo. En definitiva no se puede explicar la permanencia en base al modelo presentado.

\subsection{Crisp-Set QCA (csQCA) para acceso a la élite política gubernamental}

Se excluyen del análisis las variables de género y edad por tres razones: (a) interesa medir el mecanismo de causalidad de ciertas variables específicas; (b) se considera que el efecto de la variable edad influye más como determinante de cohesión de grupos etarios; y (c) el análisis estadístico descriptivo ha demostrado el limitado 
acceso que tienen las mujeres a posiciones institucionales relevantes, lo cual ha condicionado la regresión logística binaria mostrando que ser hombre es una variable estadísticamente significativa, sin embargo, se descarta continuar usando esta variable para evitar sesgos de selección por admisión en los mecanismos de causalidad con QCA.

El análisis causal configurativo en base a protocolo QCA arroja 127 combinaciones posibles para distintos tipos de análisis de condiciones necesarias y suficientes para acceso $(\mathrm{Y} \alpha)$. En base a un análisis de suficiencia con csQCA y un análisis lógico de implicación se descartan la mayoría de las variables alternativas para disminuir el número de combinaciones posibles.

Se mantiene dentro del análisis la variable relativa a pertenencia a centros de estudios o think tanks $\left(\mathrm{X}_{5}\right)$, pues de acuerdo a los análisis realizados la posesión de recursos técnicos sobresalientes $\left(\mathrm{X}_{2}\right)$ no presenta condición de causalidad sobre $\mathrm{X}_{5}$. Se incorpora la variable para realizar un análisis auxiliar y realizar su evaluación como posible determinante importante para el acceso o la permanencia a la élite política gubernamental.

Cabe señalar que el concepto think tank ha estado ligado desde finales de la primera mitad del siglo XX a planes de evaluación y estrategia militar, sin embargo, con el tiempo el término fue aplicado a instituciones que no sólo se enfocaban en temas de defensa y que trabajan temas políticos, económicos y sociales. Con el tiempo se ha asociado el concepto de think tank con instituciones que son protagonistas en los procesos de formulación de políticas públicas (ver McGann \& Weaver, 2002; Navarrete \& Gómez Amigo, 2011; Uña, 2006). De acuerdo a McGann y Weaver (2002) existen distintos tipos de think tanks, siendo los centros militantes y los think tanks de partidos dos tipos específicos que se caracterizan por alejarse de la noción clásica y restringida del concepto ${ }^{12}$ (ver Navarrete \& Gómez Amigo, 2011). Recientemente Medvetz (2012) se refirió al espacio de los think tanks, el cual sería un sub-espacio de producción de conocimiento que ha surgido de la intersección entre el campo político, económico, cultural (académico) y mediático.

Considerando la relevancia inesperada que arrojaron los análisis para la variable $\mathrm{X}_{5}$ es que se contempla un análisis auxiliar. Este análisis busca evaluar qué es más significativo

12 La noción clásica de los think tanks se refiere a éstos como centros autónomos que generan conocimiento independiente y mantienen una distancia y autonomía con respecto a partidos políticos y universidades. 
para efectos de acceder y/o permanecer en la élite política gubernamental: poseer efectivamente un nivel educacional elevado o verificar una trayectoria y participación en los centros de estudios o think tanks ligados a la coalición gobernante sin presentar necesariamente las mejores credenciales académicas.

Análisis de condiciones necesarias y suficientes para acceso (cs QCA)

El análisis de condiciones necesarias para acceso $(\mathrm{Y} \alpha)$ arroja que las tres mejores disyunciones inclusivas son: $\left(\mathrm{X}_{1}+\mathrm{X}_{2}\right)$ con una consistencia de 0,94 y una cobertura de 0,$55 ;\left(X_{1}+X_{5}\right)$ con una consistencia de 0,88 y una cobertura de 0,53 ; y $\left(X_{1}\right)$ con una consistencia de 0,79 y una cobertura de 0,51. Por otra parte, el análisis de condiciones suficientes para acceso $(\mathrm{Y} \alpha)$ arroja que las mejores conjunciones son: $\left(\mathrm{X}_{5}\right)$ con una consistencia de 0,71 y una cobertura de 0,$45 ;\left(\mathrm{X}_{1} \star \mathrm{X}_{5}\right)$ con una consistencia de 0,70 y una cobertura de 0,36 ; $y\left(X_{5} \star X_{3}\right)$ con una consistencia de 0,84 y una cobertura de 0,15 . Todo parece indicar que para acceder a la élite política la pertenencia a centros de estudios o think tanks $\left(\mathrm{X}_{5}\right)$ es más importante que presentar recursos técnicos sobresalientes $\left(\mathrm{X}_{2}\right)$.

Se debe considerar que en el análisis de suficiencia la mejor combinación posible para acceso $(\mathrm{Y} \alpha)$ es solo la presencia de variable relativa a pertenencia a centros de estudios o think tanks $\left(\mathrm{X}_{5}\right)$, por otra parte, presentar una trayectoria política destacada $\left(\mathrm{X}_{1}\right)$, presenta la mejor cobertura $(0,79)$ pero no la mejor consistencia $(0,51)$, es decir, explica más casos, pero muchos no son exitosos, lo que implica que no verifican acceso $(\mathrm{Y} \alpha)$ como variable dependiente.

\subsection{Crisp-set QCA para permanencia en la élite política gubernamental}

Se trabaja con dos conjuntos de datos: el primero involucra a toda la muestra ( $n$ $=199$ ); el segundo involucra solo a un segmento $(n=155)$ que excluye los casos que presentan trayectorias entre esferas, es decir, actores que durante el período estudiado se mueven entre el gobierno y el parlamento. Los actores que presentan trayectorias entre esferas verifican valores bajos en el índice de permanencia destacada en posiciones relevantes en el ejecutivo, lo cual puede generar sesgos e imprecisiones en el análisis con csQCA.

La tabla de verdad evidencia consistencias similares entre el primer y segundo conjunto de datos (ver Tabla 8). En general las consistencias se elevan en el segundo conjunto de datos, particularmente para la primera configuración. Por otra parte, la varianza más significativa, con respecto al número de casos, la presenta la cuarta 
configuración, correspondiente a casos que solo presentan una militancia política destacada $\left(\mathrm{X}_{1}\right)$. Lo anterior sucede porque en el segundo conjunto de datos se advierte un descenso importante en el número de casos y se eleva la consistencia, esto quiere decir que los actores que se excluyen del primer conjunto (actores que presentan trayectorias entre esferas) presentaban esa configuración en particular y además muchos presentaban ausencia de la variable dependiente.

Tabla 8

Tabla de verdad (truth table) csQCA en base a teorización tipológica para permanencia destacada en la élite política gubernamental (Y) $(n=199)(n=155)$

\begin{tabular}{|c|c|c|c|c|c|c|c|}
\hline Configuración & $\mathrm{X}_{1}$ & $\mathrm{X}_{2}$ & $\mathrm{X}_{3}$ & $\begin{array}{c}\text { Casos } \\
n=199\end{array}$ & $\begin{array}{c}\text { Consistencia } \\
n=199\end{array}$ & $\begin{array}{c}\text { Casos } \\
n=155\end{array}$ & $\begin{array}{c}\text { Consistencia } \\
n=155\end{array}$ \\
\hline 1 & 1 & 1 & 1 & 16 & 0,44 & 11 & 0,64 \\
\hline 2 & 1 & 1 & 0 & 45 & 0,51 & 37 & 0,57 \\
\hline 3 & 1 & 0 & 1 & 21 & 0,43 & 16 & 0,56 \\
\hline 4 & 1 & 0 & 0 & 61 & 0,51 & 39 & 0,67 \\
\hline 5 & 0 & 1 & 1 & 10 & 0,50 & 10 & 0,50 \\
\hline 6 & 0 & 1 & 0 & 16 & 0,56 & 16 & 0,56 \\
\hline 7 & 0 & 0 & 1 & 2 & 0,50 & 2 & 0,50 \\
\hline 8 & 0 & 0 & 0 & 8 & 0,50 & 7 & 0,57 \\
\hline
\end{tabular}

Nota. La consistencia determina el número de casos. Una consistencia de 0,50 , por ejemplo, quiere decir que el $50 \%$ de los casos que presenta esa configuración verifican la variable dependiente $(\mathrm{Y}=1)$. Uno significa presencia; cero, ausencia. Fuente: Elaboración propia

La tabla de verdad con la variable pertenencia a centros de estudios o think tanks $\left(\mathrm{X}_{5}\right)$ como variable alternativa en lugar de posesión de recursos técnicos sobresalientes $\left(\mathrm{X}_{2}\right)$, presenta pequeñas variaciones, pero en general se aprecia que en las configuraciones donde se presenta $\mathrm{X}_{5}$ en reemplazo de $\mathrm{X}_{2}$ hay mayor consistencia. Esto sugiere que la variable $\mathrm{X}_{5}$ resulta más importante.

Análisis de condiciones necesarias y suficientes para permanencia (csQCA)

El análisis de condiciones necesarias y suficientes del primer conjunto de datos es consistente con el análisis del segundo conjunto, sin embargo, el segundo conjunto presenta mejores niveles de consistencia. El análisis de condiciones necesarias para permanencia destacada $(\mathrm{Y})$ arroja que las mejores disyunciones inclusivas son: $\left(\mathrm{X}_{1}\right.$ $\left.+\mathrm{X}_{2}\right)$ con una consistencia de 0,94 y una cobertura de 0,$58 ;\left(\mathrm{X}_{1}+\mathrm{X}_{5}\right)$ con una 
consistencia de 0,88 y una cobertura de 0,60 ; $y\left(X_{1}+X_{3}\right)$ con una consistencia de 0,84 y una cobertura de 0,58 . El análisis de condiciones suficientes arroja que las mejores conjunciones son: $\left(\mathrm{X}_{1} \star \mathrm{X}_{5}\right)$ con una consistencia de 0,69 y una cobertura de 0,$43 ;\left(X_{5}\right)$ con una consistencia de 0,68 y una cobertura de 0,54 ; $y\left(X_{5} \star X_{3}\right)$ con una consistencia de 0,63 y una cobertura de 0,19 . Los análisis de suficiencia y condiciones necesarias muestran que las mejores combinaciones para permanencia destacada $(\mathrm{Y})$ implican una combinación entre trayectoria política destacada $\left(\mathrm{X}_{1}\right)$ y pertenencia a centros de estudios o think tanks $\left(\mathrm{X}_{5}\right)$.

\section{Conclusiones}

La hipótesis inicial sobre los factores que determinan el acceso y la permanencia de la élite política gubernamental en Chile para el período 1990-2010 ha sido parcialmente rechazada en base al modelo estadístico presentado y al análisis con csQCA. Estos factores son militancia política destacada, recursos técnicos sobresalientes y capital político familiar. Se rechaza parcialmente porque no todos los factores resultan relevantes para acceder y permanecer en la élite política gubernamental.

La regresión logística binaria evidencia la importancia que tiene ser hombre, haber nacido entre 1940 y 1950, poseer recursos técnicos sobresalientes $\left(\mathrm{X}_{2}\right)$-Magíster como mínimo- y verificar un vínculo con los centros de estudio o think tanks de la Concertación $\left(\mathrm{X}_{5}\right)$, para acceder a la élite política gubernamental. Sin embargo, el modelo falla para explicar permanencia. Por otra parte, el análisis con csQCA evidencia que la posesión de recursos técnicos sobresalientes $\left(\mathrm{X}_{2}\right)$ no posee condición de causalidad sobre la participación en centros de estudios o think tanks $\left(\mathrm{X}_{5}\right)$, además esta última variable resulta clave para acceder a la élite política gubernamental y permanecer en ella. Asimismo, el análisis con csQCA evidencia que para la permanencia también resulta importante presentar una militancia política destacada $\left(\mathrm{X}_{1}\right)$.

Los resultados de esta investigación reafirman que la tecnocracia es un fenómeno importante y fuertemente relacionado con el acceso a la élite, sin embargo, el fenómeno tecnopolítico, es decir, presentar estructuras de capital basadas en un cruce de recursos técnicos y políticos, resulta preponderante para permanecer en la élite política gubernamental. La importancia de la participación y pertenencia a centros de estudios o think tanks $\left(\mathrm{X}_{5}\right)$, como variable alternativa que cobra fuerza a lo largo del estudio forzando un análisis auxiliar, reafirma lo anterior. Esto es porque la pertenencia a think tanks no tiene relación directa con la posesión de recursos técnicos sobresalientes $\left(\mathrm{X}_{2}\right)$, lo que quiere decir que quienes accedieron $\mathrm{y} / \mathrm{o}$ 
permanecieron en la élite política gubernamental gracias a su cercanía con think tanks, no necesariamente poseían las mejores credenciales académicas.

Es importante advertir que la ventaja que obtiene la variable de pertenencia a centros de estudios o think tanks $\left(\mathrm{X}_{5}\right)$ por sobre la posesión de recursos técnicos sobresalientes $\left(\mathrm{X}_{2}\right)$ puede estar determinada por una imprecisión en la medición. Lo anterior es porque csQCA trabaja en una lógica binaria que dificulta la calibración de ciertas variables. Como la posesión de recursos técnicos se mide en base al nivel educacional alcanzado, la binarización (dicotomización) de la variable puede generar imprecisiones en su calibración, pues se asimilan varios niveles de una escala de forma dicotómica. Si bien esto podría ser controlado mediante el uso de fsQCA, mejores niveles de consistencia en la posesión de recursos técnicos sobresalientes $\left(\mathrm{X}_{2}\right)$ no disminuirán la importancia de lo que el análisis auxiliar de este trabajo ha demostrado: lo clave que resultó durante el período 1990-2010 la pertenencia a centros de estudios o think tanks de la Concertación.

La evidencia sugiere que la figura del technopol ligado a los think tanks no corresponde a la clásica figura del intelectual público. Para ser un tomador de decisiones y permanecer en cargos importantes en el ejecutivo no basta con poseer grandes credenciales académicas, un gran capital cultural o ser un tecnócrata, pues la evidencia indica que es necesario participar en los partidos y en sus centros de pensamiento. Estos centros no son autónomos, sino que se configuran como centros militantes o think tanks de partidos (ver McGann \& Weaver, 2002; Navarrete \& Gómez Amigo, 2011). Todo indica que los centros de estudio son una especie de brazo partidista donde hacen carrera los actores que poseen buen nivel educacional, pero no las mejores credenciales académicas, sin embargo, compensan aquello manifestando una gran fidelidad al sector político al cual pertenece el centro. Es probable que los think tanks, más que aportar ideas para la elaboración de políticas públicas, sean la principal fuente de reclutamiento para cargos de confianza; así se ha visto también en el actual gobierno de Sebastián Piñera. Navarrete y Gómez Amigo (2011) señalan que en la Concertación esto no sucedió con la magnitud que ha ocurrido en el actual gobierno, en el cual think tanks como Libertad y Desarrollo, la Fundación Jaime Guzmán e Instituto Libertad han tenido un protagonismo sorprendente, sin embargo, este trabajo indica que el fenómeno tuvo una magnitud altísima durante los 20 años de gobierno de la Concertación. Lo que pasa es que en la Concertación el fenómeno no fue tan evidente, principalmente porque los centros de estudio estaban más atomizados producto del movimiento masivo de 
actores que se generó desde la sociedad civil hacia el aparato estatal a comienzos de la década de 1990 cuando se recuperó la democracia (ver Delamaza, 2010, 2011).

En definitiva los think tank durante los 20 años de gobierno de la Concertación parecen haber estado excesivamente cerca del campo político, alejándose del intelectual o mediático (ver Medvetz, 2012). Así estos centros se convirtieron en un sostén para las redes de reclutamiento y parte importante de los entornos partidistas de la coalición y sus partidos políticos (ver Bourdieu, 1986; Sawicki, 2011), pero no el hogar de quienes efectivamente presentan un perfil intelectual y académico, más allá de lo meramente tecnocrático. Aquellas figuras, particularmente los intelectuales, transitan fugazmente en el campo político o sencillamente se ubican en la periferia (ver Bourdieu, 1999).

Por otra parte, el rechazo parcial de la hipótesis inicial no sólo se debe al éxito del análisis auxiliar, también se da porque la posesión de capital político familiar $\left(\mathrm{X}_{3}\right)$ no se configura como un factor determinante para acceder y/o permanecer en la élite política. Es importante señalar que esto no significa que aquella variable no sea importante, de hecho es altamente probable que exista un problema de validez con respecto a lo que esta investigación mide como capital político familiar. Este trabajo se basa en una lógica posicional de identificación y análisis de la élite, lo cual releva lo institucional obviando factores informales o extra-institucionales. Debido a la naturaleza del capital político familiar es probable que la forma en que se ha analizado no sea la mejor, sin embargo, fue la forma en que se pudo hacer considerando los datos disponibles. Sería pertinente trabajar en levantar y analizar más información sobre redes familiares y personales, particularmente si se realiza mediante un Análisis de Redes Sociales (ARS) (Hanneman \& Riddle, 2005; de Federico de la Rúa, 2005).

Por otra parte, es importante considerar que debido al índice presentado y a la metodología utilizada se produce un sesgo que hace que este trabajo se centre en los miembros de la Concertación, sin embargo, aquello resulta inevitable. Si se quiere estudiar a la élite gubernamental que controló las posiciones institucionales más relevantes en el poder ejecutivo durante el período 1990-2010 en Chile, necesariamente se debe estudiar a los miembros de la coalición que gobernó durante dicho período: la Concertación.

El trabajo tampoco deja claro en qué medida la élite estudiada difiere de la élite histórica debido al impacto de las transformaciones políticas, económicas y sociales del último medio siglo. ¿Fue reemplazada la élite existente? ¿Cuál es la relación 
entre la irrupción de los tecnócratas y la élite? Si bien no se plantea una visión diacrónica, tampoco se pretende establecer que los elencos elitarios nacen de un día a otro, de hecho se plantea que precisamente el quiebre democrático y el fenómeno de la transición generó un congelamiento y descongelamiento de la élite en Chile (ver Delamaza, 2010, 2011; Tironi \& Agüero, 1999). La evidencia de este trabajo indica que ante el auge del fenómeno tecnocrático en la década de 1980, la élite descongelada parece haberse adaptado, re-aprendiendo rápidamente los "nuevos códigos" del campo político. Si bien en un comienzo hubo tensiones, rápidamente hicieron suya y tomaron la bandera del conocimiento técnico como estandarte, poniendo a los think tanks en el corazón de sus procesos de reclutamiento. La élite chilena logra mover la barrera de lo posible disfrazando la tecnocracia, mirada con buenos ojos por la sociedad y el régimen dictatorial: así se expande la tecnopolítica. Este proceso no parece obedecer al incremento de liderazgo de quienes poseían más recursos técnicos (Delamaza, 2011), sino más bien parece ser la adaptación natural de la élite descongelada para ajustarse al "nuevo" Chile que tenía que gobernar. Que "volvía" a gobernar.

Además y más allá de los factores que resultan determinantes para acceder y/o permanecer en la élite política gubernamental, es importante tener en cuenta lo que esta investigación muestra en el apartado del análisis estadístico descriptivo. Se advierte una alta concentración en términos de los círculos y el origen social de los actores, lo cual permite suponer que se trata de personas que se conocen entre sí desde temprana edad, o que al menos presentan procesos de socialización muy similares. Lo anterior presupone fuertes cercanías entre los miembros del grupo, sobre todo si se les considera como personificaciones epistemológicas e incluso ontológicas, en la línea de lo que se podría considerar una perspectiva constructivista estructural. En resumen, aunque estas personas no se conozcan -situación bastante improbable pues se mueven en los mismos círculos sociales y en realidad es un grupo limitado en número- piensan y ven el mundo de forma similar.

En definitiva, la élite política gubernamental en el período 1990-2010 estuvo compuesta por pocos agentes que presentan una homogeneidad realmente sorprendente en cuanto a orígenes y círculos sociales. Por otra parte, a pesar de la centralidad del fenómeno tecnocrático, se evidencia la importancia del fenómeno tecnopolítico, el cual se manifiesta principalmente a través de la participación de ciertos agentes en centros de estudios ligados a la Concertación. La evidencia indica que la tecnopolítica se expande desplazando a la tecnocracia. Incluso pareciera que la tecnopolítica no es más que una nueva forma de reclutamiento que además permite 
a los partidos vestirse con un manto de conocimiento técnico y cientificidad. Finalmente, para permanecer en la élite política gubernamental las credenciales académicas pierden importancia en el tiempo y resulta relevante poseer una militancia política, e incluso más que eso, lo realmente importante es pertenecer o haber pertenecido recientemente a las directivas nacionales de los partidos políticos de la coalición. Lo cierto es que a pesar de la creciente desconfianza hacia los partidos políticos en Chile y en la región, durante 20 años los máximos cargos del poder ejecutivo fueron absolutamente controlados por los partidos políticos y por un selecto grupo de dirigentes, un grupo tan pequeño y con características tan particulares que prácticamente se configuran como una "casta", la cual naturalmente va a tender a su reproducción social, intentando perdurar en el tiempo.

\section{Referencias Bibliográficas}

Ai Camp, Roderic (1995). Political Recruitment across Two Centuries: Mexico, 1884-1991. Austin, TX:The University of Texas Press.

Ai Camp, Roderic (2002). Mexico's Mandarins. Crafting a Power Elite for the Twenty-first Century. Berkeley, CA:The University of California Press.

Ai Camp, Roderic (2006). Las elites de poder en México: perfil de una elite de poder para el siglo XXI. México, D.F:: Siglo XXI.

Aguilar, Omar (2011). "Dinero, educación y moral: el cierre social de la elite tradicional chilena”, en Alfredo Joignant \& Pedro Güell (compiladores), Notables, tecnócratas y mandarines: Elementos de sociología de las elites en Chile (1990-2010). Santiago de Chile: Ediciones Universidad Diego Portales.

Blondel, Jean, \& Müller-Rommel, Ferdinand (1997). Cabinets in West Europe. New York: St. Martin's Press.

Blondel, Jean, \& Müller-Rommel, Ferdinand (2007). "Political Elites”, en Russell J. Dalton \& Hans-Diete Klingemann (compiladores), The Oxford Handbook of Political Behavior. New York: Oxford University Press.

Bourdieu, Pierre (1984). Distinction: A Social Critique of the Judgement of Taste. Cambridge, MA: Harvard University Press.

Bourdieu, Pierre (1986). "The forms of capital”, en John G. Richardson (compilador), Handbook of Theory and Research for the Sociology of Education. New York: Greenwood.

Bourdieu, Pierre (1996). The Rules of Art: Genesis and Structure of the Literary Field. Palo Alto, CA: Stanford University Press.

Bourdieu, Pierre (1999). Intelectuales, politica y poder. Buenos Aires: Eudeba. 
Brooks, Stephen, Stasiak, Dorota, \& Zyro, Tomasz (2013). Policy Expertise in Contemporary Democracies. Surrey, England: Ashgate Publishing Limited.

Camou,Antonio (1997). "Los consejeros del príncipe. Saber técnico y política en los procesos de reforma económica en América Latina”. Nueva Sociedad. Nº 152, pp. 54-67.

Dávila, Mireya (2011). "Tecnocracia y política en el Chile posautoritario (1990-2010)", en Alfredo Joignant \& Pedro Güell (compiladores), Notables, tecnócratas y mandarines: Elementos de sociología de las elites en Chile (1990-2010). Santiago de Chile: Ediciones Universidad Diego Portales.

Delamaza, Gonzalo (2010). Construcción democrática, participación ciudadana y políticas públicas en Chile. (Doctorado en Sociología), Universidad de Leiden.

Delamaza, Gonzalo (2011). "Elitismo democrático, líderes civiles y tecnopolítica en la reconfiguración de las élites políticas”, en Alfredo Joignant \& Pedro Güell (compiladores), Notables, tecnócratas y mandarines: Elementos de sociología de las elites en Chile (1990-2010). Santiago de Chile: Ediciones Universidad Diego Portales.

Dézalay,Yves, \& Garth, Bryant G. (2002). La mondialisation des guerres de palais: la restructuration du pouvoir d'Etat en Amérique latine, entre notables du droit et "Chicago Boys". París: Seuil.

Dézalay, Yves, \& Garth, Bryant G. (2006). "Les usages nationaux d'une science «globale»: La diffusion de nouveaux paradigmes économiques comme stratégie hégémonique et enjeu domestique dans les champs nationaux de reproduction des élites d'État" Sociologie du Travail.Vol. 48, No 3, pp. 308-329. doi: 10.1016/j.soctra.2006.05.002

Dézalay,Yves, \& Garth, Bryant G. (2008). "L'impérialisme moral. Les juristes et l'impérialisme américain" Actes de la recherche en sciences sociales. Vol. 1, No 171-172, pp. 40-55. doi: 10.3917/arss. 171.0040

de Federico de la Rúa, Ainhoa (2005). "El análisis dinámico de redes sociales con SIENA". Empiria: Revista de metodología de las ciencias sociales. $\mathrm{N}^{\circ} 10$, pp. 151-184.

Dogan, Mattei (1999). "Les professions propices à la carrière politique. Osmoses, filières et viviers", en Michel Offerlé (compilador), La profession politique XIXe-XXe siècles. París: Belín.

Domínguez, Jorge I. (1996). Freeing Politics and Markets in Latin America in the 1990s. University Park: Pennsylvania State University Press.

Garretón, Manuel Antonio (1997). "What society? What sociology? The Chilean postdemocratization debate". Contemporary Sociology-a Journal of Reviews. Vol. 26, N ${ }^{\circ}$, pp. 576-579.

Garretón, Manuel Antonio (1999). "Chile 1997-1998: The Revenge of Incomplete democratization”. International Affairs. Vol. 75, No 2. doi: 10.1111/1468-2346.00071 
Garretón, Manuel Antonio (2005). "Social sciences and society in Chile: institutionalization, breakdown and rebirth". Social Science Information Sur Les Sciences Sociales. Vol. 44, N ${ }^{\circ}$ 2-3, pp. 359-409. doi: 10.1177/0539018405053292

Garretón, Manuel Antonio \& Garretón, Roberto (2010). "Incomplete Democracy in Chile: Reality Behind International Rankings". Revista de Ciencia Política. Vol. 30, No 1, pp. 115-148. doi: 10.4067/S0718-090X2010000100007

Godoy, Óscar (1999). "La transición chilena a la democracia: Pactada”. Estudios Públicos. N 74, pp. 79-106.

Goertz, Gary, \& Mahoney, James (2005). "Two-Level Theories and Fuzzy-Set Analysis". Sociological Methods Research.Vol.33, No 4,pp. 497-538. doi:10.1177/0049124104266128

González Bustamante, Bastián (2013). Trayectorias y Patrones de Carreras Políticas de Ministros en Chile (1990-2010). Ponencia preparada para el XI Congreso Nacional de Ciencia Política: "La Política en Movimiento: Estados, Democracias y Diversidades Regionales", Ciudad de Paraná, Argentina.

Grofman, Bernard, \& Schneider, Carsten Q. (2009). “An Introduction to Crisp Set QCA, with a Comparison to Binary Logistic Regression”. Political Research Quarterly. Vol. 62, No 4, pp. 662-672. doi: 10.1177/1065912909338464

Gulbrandsen, Trygve (2005). "Ideological Integration and Variation within the Private Business Elite in Norway". European Sociological Review. Vol. 21, No 4, pp. 329-344. doi: 10.1093/esr/jci023

Gulbrandsen, Trygve (2012). "Elite Integration - An Empirical Study". Historical Social Research-Historische Sozialforschung. Vol. 37, No 1, pp. 148-166.

Gulbrandsen, Trygve, \& Engelstad, Fredrik (2005). "Elite consensus on the Norwegian welfare state model". West European Politics. Vol. 28, $\mathrm{N}^{0}$ 4, pp. 898-918. doi: 10.1080/01402380500217029

Hanneman, Robert A. \& Riddle, Mark (2005). Introduction to social network methods. Riverside, CA: University of California, Riverside.

Higley, John \& Burton, Michael G. (1989). “The EliteVariable in Democratic Transitions and Breakdowns”. American Sociological Review. Vol.54,Nº 1,pp.17-32.doi:10.2307/2095659

Higley, John \& Gunther, Richard (1992). Elites and Democratic Consolidation in Latin America and Southern Europe. Cambridge: Cambridge University Press.

Higley, John \& Pakulski, Jan (1992). "Revolution and Elite Transformation in EasternEurope". Australian Journal of Political Science. Vol. 27, No 1, pp. 104-119. doi: 10.1080/00323269208402184 
Huneeus, Carlos (2005). “¿Por qué ha funcionado el presidencialismo en Chile? Factores institucionales y el liderazgo de Patricio Aylwin”. Persona y Sociedad. Vol. 19, No 2, pp. 11-54.

Joignant, Alfredo (2009, noviembre). El Estudio de las Élites: Un Estado del Arte. UDP Public Policy Series Working Papers, N¹. Recuperado el 11 de octubre de 2011, de http://www. expansivaudp.cl/publicaciones/wpapers/

Joignant, Alfredo (2011a). "El Estudio de las Élites: Un Estado del Arte”, en Marcelo Mella (compilador), Extraños en la noche: Intelectuales y usos políticos del conocimiento durante la transición chilena. Santiago de Chile: RIL editores.

Joignant, Alfredo (2011b, mayo). Las élites gubernamentales como factor explicativo de un modelo político y económico de desarrollo: el caso de Chile (1990-2009). Serie Avances de Investigación, No 87. Recuperado el 11 de octubre de 2011, de http://www. fundacioncarolina.es

Joignant, Alfredo (2011c). “Tecnócratas, technopols y dirigentes de partido: tipos de agentes y especies de capital en las elites gubernamentales de la Concertación (1990-2010)", en Alfredo Joignant \& Pedro Güell (compiladores), Notables, tecnócratas y mandarines: Elementos de sociología de las elites en Chile (1990-2010). Santiago de Chile: Ediciones Universidad Diego Portales.

Joignant, Alfredo (2011d). “The Politics of Technopols: Resources, Political Competence and Collective Leadership in Chile, 1990-2010”. Journal of Latin American Studies. Vol. 43, $\mathrm{N}^{\circ}$ 3, pp. 517-546. doi: 10.1017/s0022216x11000423

Joignant,Alfredo; Perelló, Lucas \& Torres, Javier (2012). Las fuentes del poder político. Fundamentos para una teoría del capital político a partir de la evidencia chilena. Ponencia preparada para el XXIInd World Congress of Political Science, Madrid, España.

Kadushin, Charles (1995). "Friendship Among the French Financial Elite". American Sociological Review. Vol. 60, N² 2, pp. 202-221.

McGann, James G. \& Weaver, Robert K. (2002). “Think Tanks and Civil Societies in a Time of Change". en James G. McGann \& Robert K. Weaver (compiladores), Think Tanks and Civil Societies: Catalysts for Ideas and Action. New Brunswick:Transaction Publishers.

Mainwaring, Scott (2013). “The Role of Elites”. Journal of Democracy. Vol. 5, No 1, pp. 144-146.

Marenco, André \& Serna, Miguel (2007). "Por que carreiras políticas na esquerda e na direita não são iguais? Recrutamento legislativo em Brasil, Chile e Uruguai”. Revista Brasileira de Ciências Sociais. Vol. 22, No 64, pp. 93-113. doi:10.1590/S0102-69092007000200008

Medvetz,Thomas (2012). Think Tanks in America. Chicago:The University of Chicago Press.

Mills, C. Wright (1956/2000). The Power Elite. New York: Oxford University Press. 
Navarrete, Bernardo \& Gómez Amigo, Giovana (2011). "Los centros de pensamiento (think tanks) en La Democracia Cristiana. ¿Más política que políticas?”, en Marcelo Mella (compilador), Extraños en la noche: Intelectuales y usos políticos del conocimiento durante la transición chilena. Santiago de Chile: RIL editores.

Neuhouser, Kevin (1992). "Democratic Stability in Venezuela - Elite Consensus or Class Compromise". American Sociological Review. Vol. 57, N 1, pp. 117-135.

Neuhouser, Kevin (1998). “Transitions to Democracy: Unpredictable Elite Negotiation or Predictable Failure to Achieve Class Compromise?”. Sociological Perspectives. Vol. 41, No 1, pp. 67-93. doi: 10.2307/1389354

Offerlé, Michel (1987/2004). Los partidos políticos. Santiago de Chile: LOM Ediciones.

Pakulski, Jan (2012). “Introduction: John Higley's Work on Elite Foundations of Social Theory and Politics". Historical Social Research-Historische Sozialforschung. Vol. 37, No 1, pp. 9-20.

Parkin, Frank (1984). Marxismo y teoría de clases. Una crítica burguesa. Madrid: Espasa-Calpe.

Putnam, Robert D. (1976). The Comparative Study of Political Elites. New Jersey: Prentice Hall.

Ragin, Charles C. (1987). The Comparative Method: Moving Beyond Qualitative and Quantitative Strategies. Berkeley, CA: University of California Press.

Ragin, Charles C. (2000). Fuzzy-Set Social Science. Chicago, IL: University of Chicago Press.

Ragin, Charles C. (2006). "Set relations in social research: Evaluating their consistency and coverage". Political Analysis. Vol. 14, No 3, pp. 291-310. doi: 10.1093/pan/mpj019

Ragin, Charles C. (2013). "New Directions in the Logic of Social Inquiry". Political Research Quarterly. Vol.66, No 1, pp. 171-174.

Ragin, Charles C. \& Fiss, Peer (2008). "Net Effects versus Configurations: An Empirical Demonstration", en Charles C. Ragin (compilador), Redesigning social inquiry: fuzzy sets and beyond. Chicago:The University of Chicago Press.

Rihoux, Benoit (2006). "Qualitative Comparative Analysis (QCA) and Related Systematic Comparative Methods. Recent Advances and Remaining Challenges for Social Science Research”. International Sociology. Vol. 21, No 5, pp. 679-706. doi: $10.1177 / 0268580906067836$

Rihoux, Benoît; Álamos-Concha, Priscilla; Bol, Damien; Marx, Axel \& Rezsöhazy, Ilona (2013). "From Niche to Mainstream Method? A Comprehensive Mapping of QCA Applications in Journal Articles from 1984 to 2011”. Political Research Quarterly. Vol. 66, No 1, pp. 175-184. doi: 10.1177/1065912912468269

Rihoux, Benoît, \& Marx, Axel (2013). "Qualitative Comparative Analysis at 25: State of Play and Agenda”. Political Research Quarterly. Vol. 66, N 1, pp. 167-171. 
Sawicki, Frédéric (2011). "Para una sociología de los entornos y de las redes partidistas". Revista de Sociología. $\mathrm{N}^{\circ}$ 25, pp. 37-53.

Siavelis, Peter M. (2009). "Enclaves of the Transition and Chilean Democracy". Revista de Ciencia Política. Vol. 29, No 1, pp. 3-21. doi: 10.4067/S0718-090X2009000100001

Silva, Patricio (1991). "Technocrats and Politics in Chile: from the Chicago Boys to the CIEPLAN Monks". Journal of Latin American Studies. Vol. 23, No 2, pp. 385-410. doi: 10.1017/S0022216X00014048

Silva, Patricio (1997). "Ascenso tecnocrático y democracia en América Latina”. Nueva Sociedad. $\mathrm{N}^{\circ} 152$, pp. 68-77.

Silva, Patricio (2006). “Los Tecnócratas y la Política en Chile: Pasado y Presente”. Revista de Ciencia Política. Vol. 26, N² 2, pp. 175-190. doi: 10.4067/S0718-090X2006000200010

Silva, Patricio (2009). In the Name of Reason: Technocrats and Politics in Chile. Pennsylvania: Pennsylvania State University Press.

Silva, Patricio (2011). "La elite tecnocrática en la era de la Concertación”, en Alfredo Joignant \& Pedro Güell (compiladores), Notables, tecnócratas y mandarines: Elementos de sociología de las elites en Chile (1990-2010). Santiago de Chile: Ediciones Universidad Diego Portales.

Tironi, Eugenio \& Agüero, Felipe (1999). “¿Sobrevivirá el nuevo paisaje político chileno?”. Estudios Públicos. No 74, pp. 151-168.

Uña, Gerardo (2006). “Think tanks en Argentina: sobreviviendo a la tensión entre participación y permanencia”. en Adolfo Garcé \& Gerardo Uña (compiladores), Think tanks y politicas públicas en Latinoamérica: dinámicas globales y realidades regionales. Buenos Aires: Prometeo Libros Editorial.

Uriarte, Edurne (2002). Introducción a la Ciencia Política. Madrid:Tecnos.

Vaisey, Stephen (2009). "QCA 3.0:The "Ragin Revolution” Continues". Contemporary Sociology: A Journal of Reviews.Vol. 38, No 4, pp. 308-312. doi: 10.1177/009430610903800403

Valenzuela, J. Samuel (1999). "Respuesta a Eugenio Tironi y Felipe Agüero: Reflexiones sobre el presente y futuro del paisaje político chileno a la luz de su pasado". Estudios Públicos. $\mathrm{N}^{\circ} 75$, pp. 273-290.

Williamson, John (1994). The Political Economy of Policy Reform. Washington D.C.: Institute for International Economics. 
